\title{
Research of the rheological properties of the gel based on sodium alginate for the local treatment of burns
}

\author{
Bohdana Vons ${ }^{1}$, Yuriy Melnyk ${ }^{2}$, Volodymyr Skorokhoda ${ }^{2}$, Taras Grochovuy ${ }^{1}$, Marjana Chubka ${ }^{1}$ \\ 1.I. Horbachevsky Ternopil State Medical University, Maydan Voly, 1, Ternopil, 46001, Ukraine \\ ${ }^{1}$ Department of Pharmacy Management, Economics and Technology \\ E-mail: bohdana.vons@gmail.com \\ ${ }^{2}$ Lviv Polytechnic National University; 12, S. Banbera Str., Lviv, 79013, Ukraine \\ ${ }^{2}$ Department of Chemical Technology of Plastics Processing;
}

\begin{abstract}
-gels are the most common dosage form for the local treatment of burns, which are safe and easy to use. Important gel parameters are rheological characteristics, such as shear stress, dynamic viscosity, mechanical stability that can predict the behavior of the environment in technological processes, and they are important for the creation of new and improved existing drugs.
\end{abstract}

Keywords - dynamic viscosity, mechanical stability, thixotropic properties, gels, sodium alginate.

\section{Introduction}

Burns are one of the most common types of injuries. According to the World Health Organization, 180000 deaths from burn injuries are recorded annually in the world. Burns occupy third place (up to 10\%) among all types of injuries among the civilian population and occupy about $5 \%$ of injuries on the battlefield. In 2017 from burn injuries suffered in Ukraine 7605 children [1].

The study of the range of medicinal drugs registered in the pharmaceutical market of Ukraine, according to the State Register of Medicines and the Anatomic-Therapeutic-Chemical Classification, proves the prospect and feasibility of the creation of new drugs in soft forms.

In recent years, gels are the most common dosage form for the local treatment of superficial burns that are becoming increasingly popular among soft dosage forms [1]. Gels are safe for the skin and easy to use, evenly distributed on the burns surface, forming a protective film, exhibit cooling effect upon application to the skin by evaporation of water, provide uniform release of the active pharmaceutical ingredient, and are economically affordable.

Important gel parameters are rheological characteristics, which can predict the behavior of the environment in the technological processes, and they are important for the creation of new and improved existing drugs. The rheogram estimates the type of flow, as well as the presence of thixotropic properties. It is a known fact that a thixotropic phenomenon is the slow change in the viscosity or any rheological properties caused by deformation of the material or its restoration after removing external influences. Thixotropic properties also complemented by the presence of electrolytes, $\mathrm{pH}$ and temperature [2].

Study of rheological properties important and necessary for the creation of liquid and soft medical forms [3].

The purpose of the work was to study the rheological (thixotropic) properties of the developed gel.

\section{Experimental Set-up and Procedure}

Taking into account the above and based on the results of the performed researches, the composition and technology of the combined drug in the form of a gel (base - sodium alginate 2\%) containing a water extraction from xenoderms powder and lidocaine hydrochloride was substantiated, the technological scheme of gel production was developed. 
The rheological properties of the gel were investigated using a rotatable viscometer Rheomat30 firm Contraves AG (Switzerland) using rotary type of adapter with coaxial cylinders (measuring system cone-cylinder CM 409.475, volume of the test sample was $0,9 \pm 0,1 \mathrm{~cm}^{3}$ ).

The viscometer is equipped with a liquid circulation thermostat UH-8 of the firm "MLW" (Germany). The studies were carried out in the range of speeds from 0 to $452 \mathrm{~s}^{-1}$.

The weight gel was transferred to the measuring cylinder, warmed for 20 minutes to the set temperature $\left(20{ }^{\circ} \mathrm{C}, 35{ }^{\circ} \mathrm{C}, 50{ }^{\circ} \mathrm{C}\right)$, after which the device was switched on and the cone began to rotate from the small deformation rates while fixing the viscometer's fixes. Gradually increased the speed (from 1 to 30 ) of rotation, while fixing the displays of the device. At the maximum speed (degree 30) within 15 minutes, the structural framework of the gel sample was destroyed. The device switched off, leaving the gel alone at rest for 15 minutes, after which made measurements, reducing the speed (of 30 to 1 ).

We obtained the dependence curve of the shear stress $(\tau, \mathrm{Pa})$ on the velocity gradient (Dr, $\left.\mathrm{s}^{-1}\right)$.

Shear stress $(\tau, \mathrm{Pa})$ was calculated by using the formula:

$$
\tau=\tau_{r} \cdot \alpha
$$

where: $\tau_{\mathrm{r}}$-device constant, $\mathrm{Pa} ; \alpha$ - display of the device.

The calculation of dynamic viscosity $(\eta, \mathrm{mPa} \cdot \mathrm{s})$ performed according to the formula using the data of the shear stress:

$$
\eta=\frac{\tau}{D_{r}}
$$

where: $\tau$ - shear stress, Pa; $D_{\mathrm{r}}$ - velocity gradient, $\mathrm{s}^{-1}$.

The values of mechanical stability (MS), calculated by the formula:

$$
\mathrm{MC}=\tau_{1} / \tau_{2},
$$

where: $\tau_{1}$ - the strength of the structure to fracture; $\tau_{2}$ - the strength of the structure after its destruction.

\section{Results and discussions}

Important indications of the soft dosage forms are their consistency and the ability to smear, which is related to the shear stress, as well as the stability of the gel when changing the temperature regimes of storage. The gel base should be easily applied on the damaged skin surface, have sufficient fluidity, facilitate release of the active ingredient from the dosage form. The dependence of the structure-mechanical properties of the gel on the shear rate was studied at temperatures of 20 ${ }^{\circ} \mathrm{C}, 35{ }^{\circ} \mathrm{C}$ and $50{ }^{\circ} \mathrm{C}$ in order to investigate changes in rheological parameters, as the temperature decreases the structure-mechanical and consumer characteristic of the gel (Fig. 1).

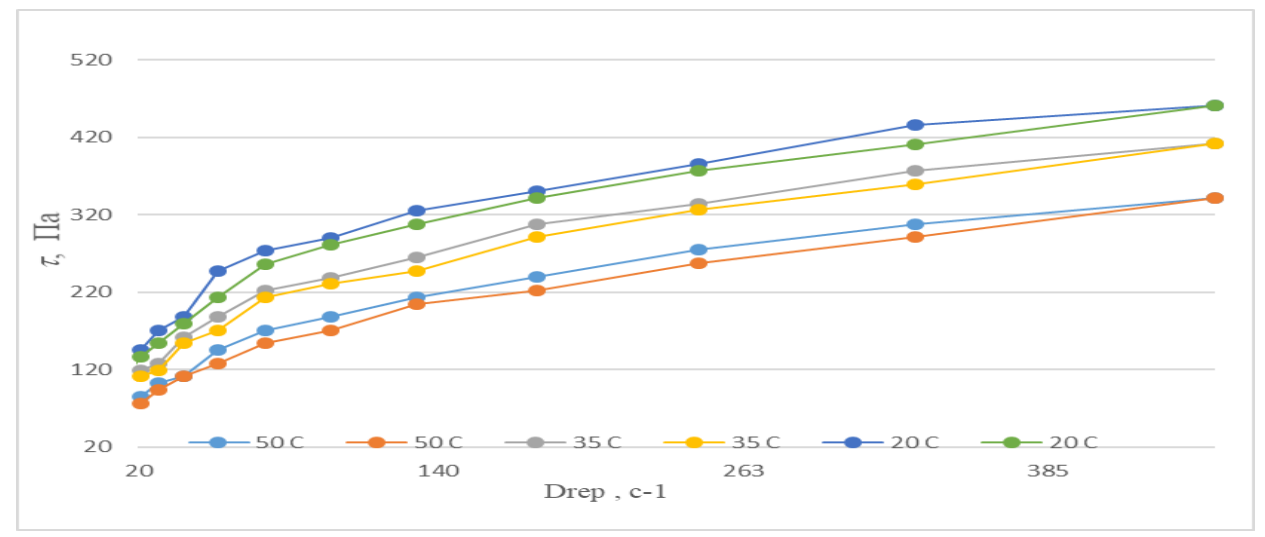

Fig.1. Rheogram of gel based on sodium alginate with lidocaine hydrochloride and water extract from xenoderms powder at a temperature of $20,35,50^{\circ} \mathrm{C}$. 
The rheogram of the experiment indicate that the gel under investigation is a non-Newtonian fluid and has a plastic type of fluidity. Figure 1 shows that gels based on sodium alginate characterized by the presence of the upper and lower curves of the flow that do not coincide with each other and form a "hysteresis loop" whose area indicates the presence of thixotropic properties despite the change in temperature regimes. At the same time, the area of the hysteresis loops is practically the same, but there is a regularity of reducing the bias voltage from the rate of displacement with increasing temperature of the experiment. With an increase in temperature up to $50{ }^{\circ} \mathrm{C}$, a slight decrease in the viscosity of the gel is observed, which can be explained by heating the polymer molecule and changing the mechanical stability of the gel.

On Figure 2 shown the parameters of structural viscosity, which is make it possible to determine its dependence on the gradient of the shear rate at temperatures $20^{\circ} \mathrm{C}, 35{ }^{\circ} \mathrm{C}$ and $50{ }^{\circ} \mathrm{C}$.

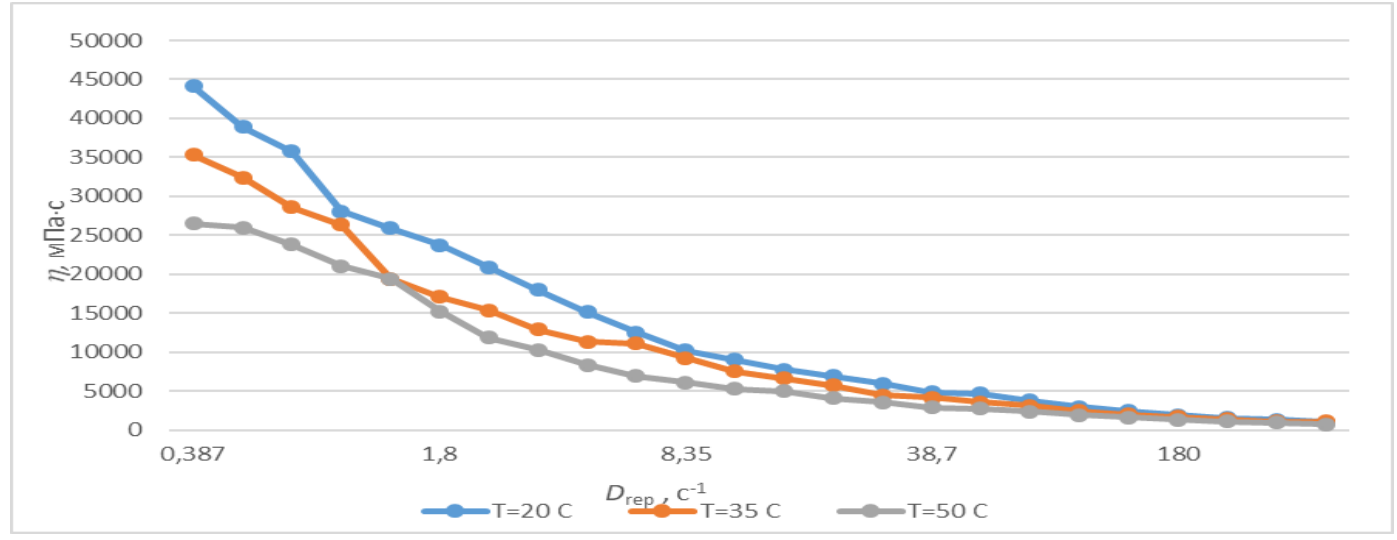

Fig.2. The dependence of the structural viscosity of the gel on the basis of sodium alginate (2\%) on the shear rate at the temperature of $20^{\circ} \mathrm{C} ., 35^{\circ} \mathrm{C} ., 50{ }^{\circ} \mathrm{C}$.

As can be seen from the data shown in Figure 2, there is a decrease in structural viscosity during the growth of the shear rate and temperature, which is logical for structured disperse systems based on sodium alginate, which in turn provides the necessary parameters of the process of gels.

Also, we have calculated the mechanical stability gels, which characterizes the degree of destruction of the polymer structure. The optimal value of mechanical stability is 1 , at a temperature of $20{ }^{\circ} \mathrm{C}-\mathrm{MS}=1,06$, at $35^{\circ} \mathrm{C}-\mathrm{MS}=1,07$, and at $50-\mathrm{MS}=1,22$, indicating no interaction between the active pharmaceutical ingredients and the base.

\section{Conclusion}

Was investigated the rheological properties of gel based on sodium alginate $(2 \%)$ which is belongs to non-Newtonian types of solutions with plastic properties and exhibits thixotropic properties. The dependence of rheological properties, namely the viscosity of the investigated gel on the change in temperature regimes, has been confirmed. Calculated values of mechanical stability of gels, which allow predicting the stability of the drug.

\section{References}

[1] B. V. Vons, M. B. Chubka, T. A. Groshovyi, "The problem of treatment of burns' wounds and characteristic of drugs for the local treatment of burns," Aktual'ni Pitannâ Farmacevtičnoï i Medičnoï Nauki ta Praktiki., vol. 1, pp. 119-125, 2018.

[2] L. W Meng et al., "Viscoelastic rheological property of different types of polymer solutions for enhanced oil recovery," J. Cent. South Univ., vol.15, pp. 126-129, 2008.

[3] F. C. Carvalho, G. Calixto, "Rheological, mechanical and bioadhesive behavior of hydrogels to optimize skin delivery system," Drug. Dev. Ind. Pharm., vol. 39, issue 11, pp. 1750-1757, 2013. 